\title{
Impact on staff of the Mentally Healthy Schools Framework
}

Julia Anwar-McHenry ${ }^{1,2}$, Catherine F Drane ${ }^{3,4}$, Phoebe Joyce ${ }^{1}$, Robert J Donovan ${ }^{5}$

${ }^{1}$ Mentally Healthy WA, Curtin University, Perth, Australia

${ }^{2}$ WA Department of Education (Teacher)

${ }^{3}$ National Centre for Student Equity in Higher Education, Curtin University, Perth, Australia;

${ }^{4}$ Behavioural Research Group (School of Public Health), Curtin University, Perth, Australia.

${ }^{5}$ University of Western Australia (School of Human Sciences), Perth, Australia. 


\section{Abstract}

Purpose - The Mentally Healthy Schools Framework, based on the population wide Act-BelongCommit mental health promotion campaign, is a whole school approach primarily targeting student mental health, but also intended for staff. This paper presents the results of an impact survey on staff after the implementation of the Framework in a number of schools in Western Australia.

Design/methodology/approach - A baseline questionnaire was completed by $n=87$ staff at schools that had just signed up to the program and a participant questionnaire was completed by $n=146$ staff at schools that had been participating for at least 17 months.

Findings - The results show that the Framework has had a substantial impact on many staff in terms of increased mental health literacy and taking action to improve their mental health.

Originality/value - Mental health interventions in schools generally focus on students' wellbeing and how to deal with student mental health problems. There are few comprehensive interventions that also include staff wellbeing.

Keywords Health promoting schools, School mental health, Mental health promotion, Project evaluation.

Paper type Research paper

Acknowledgements At the time this research was conducted, this initiative was funded by the Health Promotion Foundation of Western Australia (Healthway), the Western Australian Mental Health Commission, and Chevron Australia. 


\section{Introduction}

In an earlier article in this Journal we described the Mentally Healthy Schools Framework that was based on the population wide Act-Belong-Commit mental health promotion program adapted to a school setting via the WHO's Health Promoting Schools Framework (Anwar-McHenry et al. 2016). That paper reported a process evaluation of the initial implementation of the Framework. This paper reports on an impact evaluation of the Framework on staff in schools implementing the Framework (the impact on students is currently in preparation).

Given that many mental health problems and disorders have a peak age onset in childhood or adolescence (McGorry et al., 2007), it is widely acknowledged that schools are an important setting for mental health promotion to prevent mental health problems (Power et al., 2008). Hence the focus on mental health promotion in schools is primarily on programs for improving the students' mental health, with little attention paid to including activities or constructs for staff mental health (e.g., see Slee et al. 2012; Svane et al. 2019). Where staff programs do exist, they are often just separate workshops or guidelines about dealing with school matters that may cause stress to staff.

However, the mental health and wellbeing of teachers is an occupational health concern. Work related stress can affect productivity, job satisfaction, and even workplace violence (Quick \& Tetrick, 2011). Amongst teachers, work related stress is a major risk factor for mental health issues such as anxiety and depression (Chan, 2002; Johnson et al 2005; Kyriacou, 2001). Further, teachers' mental illhealth may impact students' learning, inhibit the development of supportive teacher-student relationships, and influence teachers' ability to recognise and support the mental health needs of their students (Kidger et al.,2010; Sisask et al., 2014). In particular, students from disadvantaged backgrounds, who are at a greater risk of developing mental illness (Reiss, 2013), may rely more heavily on their teachers for emotional support. Consequently, an additional burden is placed on teachers to manage these vulnerable students, creating a further source of workplace stress and distress (Rothi, Leavey, \& Best, 2008).

Given recent findings on the mental health of school teaching staff reporting higher levels of psychological distress than in the general population (Stapleton et al. 2020), there is a clear need for school programs to consider targeting the mental health of staff. The Mentally Healthy Schools Framework introduced in Western Australia uses the WHO guidelines for Health Promoting Schools (Quirke 2015) to embed the "Act-Belong-Commit" community-wide mental health promotion campaign into the school setting. This whole-of-school approach aims to not only improve the mental health of students, but also the mental health of teachers and other staff. The whole-of-school approach shifts the focus from mental ill-health to the promotion of a culture of mental health and wellbeing that is prioritized across the whole school community (Sisask et al., 2014).

The Act-Belong-Commit program and the Mentally Healthy Schools Framework (MHSF) have been described in detail in Anwar-McHenry et al. (2016). However, we present brief descriptions of these below.

\section{The Act-Belong-Commit Community-wide campaign}

Act-Belong-Commit is a comprehensive community-based mental health promotion campaign designed to build population mental health and prevent mental illness (Donovan \& Anwar-McHenry 2014; Donovan et al. 2006). The campaign encourages individuals to engage in mentally healthy activities, while at the same time using a social franchising approach to support and encourage organisations that offer mentally healthy activities to promote and increase participation in these activities (Donovan 2021). The campaign is directed by Mentally Healthy WA (MHWA) at Curtin 
University, and implemented through partnerships with health services, local/state governments, schools, workplaces, community organisations, and local clubs.

As the brand name suggests, people can build positive mental health and resilience by: keeping physically, mentally, spiritually and socially active (Act); keeping up contacts with friends and family and participating in community events (Belong); and taking on challenges or causes that provide meaning and purpose in their lives (Commit). There is substantial evidence that these three domains contribute to increasing levels of positive mental health (and in fact, to physical health) (Donovan \& Anwar-McHenry 2014; Santini et al. 2017; Santini et al. 2018).

The Act-Belong-Commit campaign's fundamental messages are also consistent with recent broader conceptions around mental health literacy (Kutcher et al 2016), in that they are designed to increase positive mental health by enhancing people's understanding of factors that impact on mental health, and empowering them to take action to improve and maintain their mental health.

\section{The Act-Belong-Commit Mentally Healthy Schools Framework}

The Mentally Healthy Schools Framework (MHSF) encourages a whole-of-school approach to mental health promotion through the three domains of the WHO's Health Promoting Schools Framework. The MHSF seeks to increase knowledge and skills of school staff to create mentally healthy school environments, to change both staff and student behaviour and attitudes with respect to mental health and mental illness, strengthen community links with the school, enhance meaning and purpose of activities and events in which the students already participate, and increase student connectedness to, and teacher morale within, the school (Anwar-McHenry et al. 2016).

Schools receive promotional strategies and resources targeting the whole school community. The flexible program is self-sustaining and complements areas of the Australian Curriculum, allowing schools freedom to tailor the MHSF to school priorities and needs, thus minimising the burden on staff. Partner schools engage in formal training conducted by Act-Belong-Commit and receive a copy of the Mentally Healthy Schools Handbook, resources, signage, and merchandise to the value of $\$ 150$ to assist with the delivery of the MHSF.

In 2016 and 2017, surveys of staff and students at participating secondary schools were undertaken using structured self-completion questionnaires. This paper reports on the staff survey findings.

\section{Methods}

\section{Sample}

Commencing in 2016, secondary schools that had either recently signed up or who had been a partner for at least 17 months were invited to participate in the impact evaluation. Of the 20 schools meeting these criteria, nine agreed to distribute questionnaires to staff and/or students in the time frame allowed for schools to respond to the request. Eight of these nine schools distributed questionnaires to staff.

The schools forwarded the questionnaire plus consent form to their staff via email for printing and self-completion. The Act-Belong-Commit Schools Project Officer attended several staff meetings and distributed and collected a number of self-completed questionnaires. All survey respondents had the opportunity to go into a draw to win a prize as an incentive for completion of the questionnaire. Data collection occurred from late 2016 to mid - 2017 


\section{Questionnaires}

A 'baseline' questionnaire was completed by staff at schools that had just signed up to the program and a 'participant' questionnaire was completed by staff at schools that had been participating for at least 17 months. This report focuses on the participant survey results, with comparisons to the baseline survey results where appropriate.

Both questionnaires covered the same topics, beginning with several general questions about mental and physical health, and then focusing on awareness and understanding of the Act-Belong-Commit campaign in general; awareness of the school's involvement in the Act-Belong-Commit MHSF; whether those aware of the campaign had tried to do something for their mental health as a result of the campaign; whether, and if so how it had changed the way they think about mental health; whether they had talked about mental health and/or the campaign with their students, other staff, friends and family; and whether they believed that the campaign at the school had increased openness about mental health amongst staff and students and decreased stigma around mental illness. There were 24 topic questions along with three background questions (position at the school, age, gender) (see Anwar-McHenry et al. 2018 for baseline and participant questionnaires for students and staff).

This research was granted ethics approval from Curtin University's Human Research Ethics Committee (Approval RDHS-216-15) and the Department of Education (Approval D16/0023499).

\section{Results}

\section{Sample characteristics}

$\mathrm{N}=146$ staff from six schools that had been implementing the MHSF for at least 17 months completed staff 'participant' questionnaires, and $\mathrm{N}=87$ staff from two schools that had only recently signed up as Act-Belong-Commit partners completed 'baseline' staff questionnaires. Approximately half of all respondents were in the 30-49 years age bracket, two-thirds were female, and just over $70 \%$ were teaching staff.

\section{Campaign awareness and understanding}

Both 'baseline' and 'participant' respondents were asked: "Have you heard of the Act-Belong-Commit campaign?". Consistent with annual statewide population surveys (Lin et al. 2020), 77\% of baseline respondents reported being aware of the campaign, whereas awareness amongst the participant respondents was $92 \%$. That is, their school's involvement in the Act-Belong-Commit campaign appears to have increased staff awareness of the campaign.

Those aware of the campaign were asked "What does Act-Belong-Commit mean? What is the campaign trying to do?" Both baseline and participant responses were consistent with the campaign messages: 'keep active, 'do something'; 'join a club or group', 'get involved in community', 'bring people together', 'have purpose', commit to goals'.

\section{Campaign impact on behaviour}

\section{Did something for their mental health as a result of the campaign}

When those aware of the campaign were asked whether they 'had done or tried to do something for their mental health as a result of becoming aware of the Act-Belong-Commit message, approximately twice as many participant respondents as baseline respondents responded 'yes': $43 \%$ vs $21 \%$. Even allowing for a sampling bias, these data indicate that the campaign has had a significant impact on staff in the schools where the MHSF has been implemented for some time. 


\section{Talked with others about mental health or the campaign}

When participant respondents aware of the campaign were asked whether, as a result of the campaign, they had talked more about mental health with various others, almost half reported talking more about mental health with friends and/or family (48\%) and other school staff (45\%). Also, $41 \%$ reported talking about Act-Belong-Commit with family and friends and 39\% reported talking about Act-Belong-Commit with students. These results indicate that the MHSF has stimulated increased openness about talking about mental health in these schools.

\section{Impact on beliefs about mental health}

Impact on how they think about mental health: When participant respondents aware of the campaign were asked whether they 'had changed the way they think about mental health as a result of the ActBelong-Commit message', just over two in five (43\%) staff responded 'yes'. When asked 'in what way their thoughts had changed', their responses generally related to one or more themes such as: an increased awareness and clearer understanding of mental health; being more proactive about keeping mentally healthy; being encouraged to engage in self-help activities; and being more willing to talk about mental health issues and support others experiencing problems.

Perceived impact on openness around mental health: Participant respondents were asked whether they thought the Act-Belong-Commit campaign at the school had made staff and students more open about mental health issues, less open, or made no difference'. These results are shown in Table 1. Table 1 shows that almost two-thirds of participant staff (62\%) believed the campaign had made students more open about mental health issues, and just under half believed the campaign at the school had made staff more open about mental health issues. For each case, none said, 'less open', with approximately one in four stating 'don't know'.

Table 1. Perceived impact of Act-Belong-Commit Campaign at the School on student and staff openness about mental health issues

\begin{tabular}{lcc} 
& $\begin{array}{c}\text { Perceived impact } \\
\text { on student } \\
\text { openness about } \\
\text { mental health } \\
\text { issues }\end{array}$ & $\begin{array}{c}\text { Perceived } \\
\text { impact on staff } \\
\text { openness about } \\
\text { mental health } \\
\text { issues }\end{array}$ \\
\hline More open & 62 & 44 \\
No difference & 13 & 21 \\
Less open & 0 & 0 \\
Don't know/can't say & 24 & 27 \\
Not stated & 1 & 8 \\
& $100 \%$ & $100 \%$ \\
\hline
\end{tabular}

Perceived impact on stigma around mental illness: Baseline and participant respondents aware of the campaign were asked whether they thought the campaign in general or at the school respectively, had reduced, increased, or made no difference to the stigma associated with mental illness. Their responses are shown in Table 2. Table 2 indicates that the campaign at the school has likely had a substantial impact on perceived (and hence actual) stigma reduction, with 65\% of participant respondents nominating a stigma reduction impact at the school versus $46 \%$ of baseline staff nominating a stigma reduction impact in general. Further, there was a correspondingly substantial 
decline in 'don't know' from $36 \%$ 'in general' to $18 \%$ 'at the school'. None reported a perception of increased stigma.

Table 2. Perceived impact of the campaign on stigma around mental illness

$\begin{array}{ll}\text { Baseline - } & \text { Participant - } \\ \text { in general } & \text { at school }\end{array}$

\begin{tabular}{lcc} 
& $\begin{array}{c}\text { \% Aware } \\
\text { (n= 67) }\end{array}$ & $\begin{array}{c}\text { \% Aware } \\
(\mathbf{n}=\mathbf{1 3 5})\end{array}$ \\
\hline Reduced stigma & 46 & 65 \\
No difference & 18 & 16 \\
Increased stigma & 0 & 0 \\
Don't know/can't say & 36 & 18 \\
Not stated & 0 & 1 \\
& $100 \%$ & $100 \%$ \\
\hline
\end{tabular}

\section{Staff attitude to the campaign at their school}

Participant respondents were asked how they felt about their school's involvement in the Act-BelongCommit campaign and were provided with the response categories: Very much approve; Approve; No feelings either way; Disapprove; Very much disapprove. Almost $90 \%$ approved of the school's involvement (61\% 'very much'), 10\% were 'neutral' and none 'disapproved'.

\section{Discussion}

As a result of the campaign in the general community, there was substantial prior awareness of the Act-Belong-Commit campaign amongst baseline respondents: $77 \%$. However, amongst participant respondents, awareness was almost universal: $92 \%$. Further, those aware of the campaign, had understandings of the campaign that were consistent with the campaign messages (e.g., 'take part in activities', 'bring people together', 'commit to a cause', etc). These data indicate that the schools intervention has not only increased awareness of the Act-Belong-Commit campaign among staff in participating schools, but also increased mental health literacy in these staff.

General population impact evaluations tend to report that $12-18 \%$ of those aware of the campaign have tried to do something for their mental health as a result of exposure to the campaign. The baseline percentage of staff was somewhat higher than the general population at $21 \%$, but considerably higher amongst participant staff: $43 \%$. While the absolute percentages may reflect some respondent selection bias and we do not have pre-intervention data for the participant respondents, this substantial increase amongst participant staff can be taken as consistent with an intervention effect. In addition to enhancing staff mental health, these participant staff results are very positive given that staff are role models for their students, and that staff who internalise and act on a message are then far more likely to promote that message to their students than staff who only endorse the message.

As in the general population evaluation, the schools intervention is also facilitating staff talking about mental health and/or the Act-Belong-Commit campaign with friends, family, students, and colleagues. Hence it may well be that a module dealing with 'talking to students about Act-Belong-Commit/mental 
health' could be developed and provided to staff to guide these interactions in a more effective manner.

Just under half of participant staff (43\%) reported changing the way they think about mental health, and in desired ways such as an increased awareness about mental health, an increased importance placed on mental health, and in taking up activities for their mental health. These data reinforce the conclusion that the MHSF intervention has the potential to contribute significantly to staff being proactive about strengthening and maintaining their own mental health.

Similarly, the results with respect to perceived reduction of mental illness stigma and increased openness with respect to mental health issues have longer term implications for increased early help seeking, and hence the prevention of more serious disorders.

None of the staff disapproved of their school's involvement with Act-Belong-Commit and almost $90 \%$ 'approved', with just under two-thirds registering strong approval. These data indicate that wider dissemination of the schools program would be looked on very favourably by staff.

\section{Conclusions}

The findings of this initial evaluation indicate that the Act-Belong-Commit MHSF intervention has considerable potential for having a positive impact on staff mental health and hence resilience to stress. All staff aware of the campaign had a good understanding of the campaign messages, a substantial proportion had taken action to enhance their mental health as a result of exposure to the messages, and substantial proportions reported a decreased stigma around mental illness and an increased self-efficacy with respect to their mental health. Subsequent studies should include prepost comparisons, formal measures of mental health literacy and validated scales to directly assess changes in mental health and wellbeing.

Overall, these and other results indicate that the Act-Belong-Commit Mentally Healthy Schools Framework has the potential to provide a means to simultaneously enhance both staff and student mental health.

\section{Limitations of this Report}

This report is primarily an impact evaluation of the initial implementation of the MHSF, not an outcome evaluation. Within that context, results for the baseline and participant surveys should be looked at independently rather than considered equivalent to a study reporting on the same sample of individuals measured at baseline and follow-up. 


\section{References}

Anwar-McHenry, J., Donovan, R.J., Nicholas, A., Kerrigan, S., Francas, S., \& Phan, T. (2016). Implementing a Mentally Healthy Schools Framework based on the population wide Act-BelongCommit mental health promotion campaign. Health Education, 116 (6), 561 - 579. http://dx.doi.org/10.1108/HE-07-2015-0023.

Anwar-McHenry, J., Joyce, P., Drane, C., \& Donovan, R.J. (2018). Mentally Healthy WA's Act-BelongCommit Schools Initiative: Impact Evaluation Report. Perth: Mentally Healthy WA, Curtin University.

Chan, D.W. (2002). Stress, self-efficacy, social support and psychological distress among prospective Chinese teachers in Hong Kong. Educational Psychology, 22, 557-569.

Donovan, R.J. (2021). Social Franchising Approaches for Community Health. In Newton-Ward, M (Eds), The Palgrave Encyclopedia of Social Marketing, Springer.

Donovan, R.J. and Anwar McHenry, J. (2014). Act-Belong-Commit: Lifestyle medicine for keeping mentally healthy. American Journal of Lifestyle Medicine, 8 (1), 33-42.

Donovan, R.J., James, R., Jalleh, G. \& Sidebottom, C. (2006). Implementing mental health promotion: the Act-Belong-Commit Mentally Healthy WA campaign in Western Australia. International Journal of Mental Health Promotion, 8 (1), 29-38.

Johnson, S., Cooper, C., Cartwright, S., Donald, I., Taylor, P., \& Millet, C. (2005). The experience of work-related stress across occupations. Journal of Managerial Psychology, 20, 178-187.

Kidger, J., Gunnell, D., Biddle, L., Campbell, R., \& Donovan, J. (2009). Part and parcel of teaching? Secondary school staff's views on supporting student emotional health and well-being. British Educational Research Journal, 36(6), 919-935.

Kutcher, S., Wei, Y., \& Coniglio, C. (2016). Mental Health Literacy: Past, Present, and Future. Canadian Journal of Psychiatry, 61 (3), 154-158.

Kyriacou, C. (2001). Teacher Stress: Directions for Future Research. Educational Review, 53 (1), 27-35.

Lin, C., Jalleh, G., Donovan, R.J. (2020). Evaluation of the Act-Belong-Commit Mentally Healthy WA Campaign: 2019 Survey Data. Behavioural Research Group, School of Public Health, Faculty of Health Sciences, Curtin University, Perth.

McGorry, P., Purcell, R., Hickie, I. \& Jorm, A. (2007). Investing in youth mental health is a best buy. Medical Journal of Australia, 187(7), S5-S7.

Power, M., Cleary, D. \& Fitzpatrick, C. (2008). Mental health promotion in Irish schools: a selective review. Advances in School Mental Health Promotion, 1(1), 5-15.

Quick, J. C., \& Tetrick, L. E. (Eds.). (2011). Handbook of occupational health psychology (2nd ed.). American Psychological Association.

Quirke, M.B.C. (2015). An evaluation of the effect of a health promoting school approach, The Healthy Schools Programme, on the psychological health and well-being of primary school-aged children", PhD Dissertation, Department of Psychology, National University of 
Ireland, Maynooth.

Reiss, F. (2013). Socioeconomic inequalities and mental health problems in children and adolescents: A systematic review. Social Science \& Medicine, 90, 24-31.

Rothi, D.M., Leavey, G., \& Best, R. (2008). On the front-line: Teachers as active observers of pupils' mental health. Teaching and Teaching Education, 24, 1217-31.

Santini, Z.I., Koyanagi, A., Tyrovolas, S., Haro, J.M., Donovan, R.J., Nielsen, L., \& Koushede, V. (2017). The protective properties of Act-Belong-Commit indicators against incident depression, anxiety, and cognitive impairment among older Irish adults: Findings from a prospective community-based study. Experimental Gerontology, 2017.02.074. http://dx.doi.org/10.1016/j.exger.

Santini, Z.I., Koyanagi, A., Donovan, R.J., Hindrichsen, C., Nielsen, L., \& Koushede, V. (2018). ActBelong-Commit indicators promote subjective wellbeing among older Irish adults: A prospective community-based cohort study. American Journal of Health Behavior, 6 (31-45). DOI: https://doi.org/ 10.5993/AJHB.42.6.4

Sisask, M., Värnik, P., Värnik, A., Apter, A., Balazs, J., Balint, M., Bobes, J., Brunner, R., Corcoran, P., Cosman, D., Feldman, D., Haring, C., Kahn, J.P., Postuvan, V., Tubiana, A., Sarchiapone, M., Wasserman, C., Carli, V., Hoven, C.W., \& Wasserman, D. (2014). Teacher satisfaction with school and psychological well-being affects their readiness to help children with mental health problems. Health Education Journal, 73, 382-393.

Slee, P.T., Dix, K.L. \& Askell-Williams, H., 2012. Whole school mental health promotion in Australia. The International Journal of Emotional Education, 3(2), 37-49.

Stapleton, P., Garby, S., \& Sabot, D. (2020). Psychological distress and coping styles in teachers: A preliminary study. Australian Journal of Education, https://doi.org/10.1177/0004944120908960.

Svane, D., Evans, N., Carter, M.A. (2019). Wicked wellbeing: Examining the disconnect between the rhetoric and reality of wellbeing interventions in schools. Australian Journal of Education, 0(0), 1-18. https://doi.org/10.1177/0004944119843144. 